\title{
Triguilho na alimentação da tilápia do nilo (Oreochromis niloticus L.): digestibilidade e desempenho
}

\author{
Wheat midlings in the nile tilapia feeding (Oreochromis niloticus L.): digestibility and performance
}

\author{
Arcangelo Augusto Signor ${ }^{\mathrm{I}}$ Wilson Rogério Boscolo ${ }^{\mathrm{I}}$ Aldi Feiden ${ }^{\mathrm{I}}$ Altevir Signor ${ }^{\mathrm{II}}$ \\ Adilson Reidel ${ }^{\mathrm{II}}$
}

\section{RESUMO}

No presente experimento objetivou-se determinar os coeficientes de digestibilidade aparente (CDa) da proteína bruta $(P B)$ e da energia bruta (EB) do triguilho para a tilápia do Nilo (Oreochromis niloticus) e avaliar a inclusão do triguilho sobre o desempenho de alevinos de tilápia do Nilo. Para a determinação dos CDa, foram utilizadas 40 tilápias com peso e comprimento médios de $80,00 \mathrm{~g}$ e $15,9 \mathrm{~cm}$, respectivamente, submetidas à coleta das fezes por sedimentação. Para a avaliação do desempenho, foram utilizados 125 alevinos de tilápia do Nilo, com peso inicial médio de $0,80 \mathrm{~g}$, distribuídos em 25 aquários com capacidade de $30 \mathrm{~L}$, em um delineamento inteiramente casualizado, com cinco tratamentos e cinco repetições. As rações experimentais continham níveis de inclusão de 0,00; 7,97; 14,94; 23,91 e 31,88\% de triguilho substituindo até $100 \%$ do milho. Os CDas da PB e EB do triguilho foram de 91,03 e 78,72\%, respectivamente, apresentando $11,92 \%$ de proteína digestível e $3134 \mathrm{Kcal} \mathrm{kg}^{-1}$ de energia digestível. Não foi observada diferença $(P>0,05)$ no desempenho dos peixes alimentados com as rações contendo os diferentes níveis de inclusão do triguilho. O triguilho é um alimento com bons CDa da PB e EB e pode ser incluído em até 31,88\% em rações para alevinos de tilápia do Nilo sem causar prejuízo no desempenho.

Palavras-chave: alimento alternativo, desempenho, digestibilidade, tilápia, triguilho.

\section{ABSTRACT}

This experiment was aimed at determining the apparent digestibility coefficients $(A D C)$ of the raw protein $(R P)$ and of raw energy (RE) of the wheat middling given to the Nile tilapia (Oreochromis niloticus) and evaluating the inclusion of wheat middling on the performance of Nile tilapia fingerlings. In order to determine the ADC, 40 tilapias with the average weight and length of $80 \mathrm{~g}$ and $15.9 \mathrm{~cm}$, respectively, were used and submitted to the collection of the excrements by sedimentation. To the evaluation of the performance 125 fingerlings of Nile tilapia were used, with an initial average weight of $0.80 \mathrm{~g}$, distributed into 25 aquariums with a $30 \mathrm{~L}$ capacity at a random design, with five treatments and five repetitions. The experimental fish feed had inclusion levels of $0.00 ; 7.97 ; 14.94 ; 23.91$ and $31.88 \%$ of wheat middling, substituting corn up to $100 \%$. The ADCs of RP and RE of the wheat middling were $91.03 \%$ and 78.72 , respectively, presenting $11.92 \%$ of digestible protein and $3134 \mathrm{kcal} \mathrm{kg}^{-1}$ of digestible energy. No difference was observed $(P>0.05)$ in the performance of the fish fed with the fish feed having the different levels of inclusion of the wheat middling. The wheat middling is a feed with good $A D C$ of $R P$ and RE and can be included in up to $31.88 \%$ in fish food for Nile tilapia fingerlings without causing damage in its performance.

Key words: alternative food, digestibility, performance, tilapia, wheat middling.

\section{INTRODUÇÃO}

A tilápia do Nilo é uma espécie de origem Africana (CASTAGNOLLI, 1992), com potencial para as regiões tropicais e subtropicais (EL-SAYED, 1999), apresenta versatilidade e crescimento rápido (HAYASHI et al., 1999) e não apresenta espinhos em “y” em seu filé (HILDSORF, 1995), sendo atualmente a segunda espécie mais cultivada mundialmente (BORGHETTI et al., 2003).

O custo com alimentação, nos sistemas de piscicultura intensivos, superam 50\% dos custos operacionais de produção (EL-SAYED, 1999). Portanto,

'Universidade Estadual do Oeste do Paraná (Unioeste), Rua da Faculdade, 645, 85903-000, Toledo, PR, Brasil. E-mail: aasignor@pop.com.br. Autor para corresondência.

IUniversidade Estadual Paulista (Unesp), São Paulo, Brasil. 
pesquisas para avaliação nutricional de alimentos alternativos visam a diminuir custos com alimentação e viabilizar a produção (DEGANI \& REVACH, 1991). O conhecimento da digestibilidade da energia e nutrientes dos alimentos alternativos permite a formulação de rações com mínimo custo, que atendam às exigências nutricionais dos animais (SULLIVAN \& REIGH, 1995; AKSNES \& OPSTVEDT, 1998). Portanto, a digestibilidade é uma técnica relevante do estudo na nutrição, que permite avaliar a hidrólise e/ou digestão do alimento, quantificando a disponibilidade de nutrientes.

O trigo geralmente é cultivado em estações frias, sendo que a ocorrência de geadas, em determinadas fases de seu desenvolvimento, podem ocasionar prejuízos no desenvolvimento dos grãos. Este fato ocasiona variações em sua composição física e química, podendo resultar em um subproduto de menor valor de mercado chamado triguilho. Este alimento não é utilizado para alimentação humana, pois apresenta alterações no seu padrão de qualidade, como coloração e grande percentagem de grãos fragmentados, malgranados ou chochos, podendo ser um alimento alternativo para ser utilizado na alimentação de animais (BARBOSA et al., 1990). Este alimento apresenta valores de proteína bruta, aminoácidos e fibra bruta superiores aos apresentados pelo milho; no entanto, apresenta menores valores de energia digestível para suínos (DE BRUM et al., 1998).

Devido à maior parte dos custos de produção de peixes ser representada pela alimentação (LUTZ, 2000; BOSCOLO et al., 2001; MEURER et al., 2002), é de fundamental importância avaliar os alimentos alternativos regionais. Portanto, este trabalho foi realizado com o objetivo de determinar os coeficientes de digestibilidade aparente do triguilho para a tilápia do Nilo e avaliar o desempenho dos alevinos de tilápia alimentados com rações contendo diferentes níveis de inclusão de triguilho substituindo parcial e totalmente o milho.

\section{MATERIAL E MÉTODOS}

Os experimentos foram realizados no Laboratório de Aqüicultura da Universidade Estadual do Oeste do Paraná (UNIOESTE), Campus de Toledo. No experimento 1, para a determinação dos coeficientes de digestibilidade aparente (CDa), foram utilizadas 40 tilápias com peso e comprimento médio de $80,00 \pm 15,97 \mathrm{~g}$ e $15,90 \pm 1,87 \mathrm{~cm}$, respectivamente. Este experimento foi executado no período de 25/02 a 10/03/2003. Os animais foram alojados em dois tanques-rede circulares, dentro de duas caixas plásticas com 310L. Nesta estrutura, os peixes permaneceram durante todo o período de adaptação e durante o dia na fase de coleta. Esta metodologia foi realizada para evitar o contato dos peixes com restos de rações e fezes.

Para a coleta das fezes foi utilizada a metodologia de sedimentação, na qual os tanques-rede com os animais eram transferidos para os tanques de forma afunilada, com capacidade de 90L. Estes tanques foram equipados com copo coletor na parte inferior, onde ficavam depositadas as fezes. Foi considerado como uma unidade experimental um tanque contendo 20 animais.

Os animais foram submetidos a um período de adaptação de sete dias para a ração-referência e a ração-teste. No período de adaptação, as rações experimentais foram fornecidas à vontade, quatro vezes ao dia, às 8, 11, 14 e 17 horas. Durante o período de coleta, os peixes receberam alimentação às 8 e 14 horas, sendo que, das 17 às 20 horas, receberam alimentação à vontade, em intervalos de 15 minutos. Após 20 minutos da última refeição, os tanques-rede com os peixes eram transferidos para as cubas de coleta. Este manejo foi realizado para evitar o regurgitamento da ração. As fezes foram coletadas sempre às 7 horas da manhã do dia seguinte, durante sete dias.

Para a determinação do CDa, foi utilizada a metodologia indireta, utilizando-se como indicador o óxido crômico $\left(\mathrm{Cr}_{2} \mathrm{O}_{3}\right)$ (NRC, 1993), incorporado na proporção de $0,1 \%$ nas rações. A determinação da concentração de óxido crômico nas fezes e nas rações foi realizada por espectrofotometria de absorção atômica, segundo a metodologia de KIMURA \& MILLER (1957). O cálculo dos CDas do triguilho foi realizado de acordo com as equações de MUKHOPADHYAY \& RAY (1997) e do NRC (1993).

As fezes coletadas foram armazenadas em frascos plásticos e congeladas para posteriores análises de proteína bruta (PB), energia bruta (EB), matéria seca (MS) e cromo. Também foram analisadas as rações referência e teste, assim como o triguilho, quanto a PB, EB, MS, matéria mineral (MM) e extrato etéreo (EE). Para as análises bromatológicas, as fezes foram descongeladas, secadas em estufa de circulação forçada a $55^{\circ} \mathrm{C}$, por 24 horas, peneiradas para a retirada das escamas e moídas, e a análise bromatológica foi realizada segundo a metodologia de SILVA (1990).

Para a determinação da CDa, os peixes foram alimentados com uma ração referência e outra ração teste com inclusão do triguilho, conforme tabela 1 . O $\mathrm{pH}$, a condutividade e o oxigênio dissolvido da água foram monitorados a cada três dias às 7 horas e 30 minutos, e a temperatura foi monitorada diariamente às 7 horas e 30 minutos e às 16 horas e 30 minutos. 
Tabela 1 - Composição percentual das rações utilizadas para a determinação dos coeficientes de digestibilidade aparente de triguilho.

\begin{tabular}{lcc}
\hline Ingredientes & $\begin{array}{c}\text { Ração referência } \\
(\%)\end{array}$ & $\begin{array}{c}\text { Ração teste } \\
(\%)\end{array}$ \\
\hline Albumina & 32,00 & 22,40 \\
Gelatina & 7,70 & 5,39 \\
Antioxidante (BHT) & 0,02 & 0,02 \\
Amido de milho & 44,68 & 30,93 \\
Celulose & 5,00 & 3,50 \\
Fosfato bicálcico & 3,00 & 2,10 \\
Óleo de soja & 6,00 & 4,20 \\
Suplemento (min + vitam.) & 1,00 & 1,00 \\
Sal & 1,00 & 0,50 \\
Óxido crômico $\left(\mathrm{Cr}_{2} \mathrm{O}_{3}\right)$ & 0,50 & 0,10 \\
Triguilho & 0,10 & 29,86 \\
Total & - & 100 \\
\hline
\end{tabular}

${ }^{1}$ Níveis de garantia por quilograma do produto: Vit. A, 500.000UI; Vit. $D_{3}$, 200.000UI; Vit. E, 5.000mg; Vit. K3, 1.000mg; Vit. B1, 1.500mg; Vit. B2, 1.500mg; Vit. B6, 1.500mg; Vit. B12, 4.000mg; Ác. Fólico, 500mg; Pantotenato Ca, 4.000mg Vit. C, 15.000mg; Biotina, 50mg; Inositol, 10.000; Nicotinamida, 7.000; Colina, 40.000mg; Co, 10mg; Cu, 500mg; Fe, 5.000mg; I, 50mg; Mn, 1500mg; Se, Se, 10mg; Zn,5.000mg.

No experimento 2, para avaliação de desempenho dos alevinos de tilápia do Nilo (Oreochromis niloticus L.), no período de 26/11 a 23/ 12/2003. Foram utilizados 125 alevinos com peso inicial médio de $0,80 \pm 0,03 \mathrm{~g}$, distribuídos em 25 aquários com capacidade de 30L de volume útil, em um delineamento inteiramente casualisado, com cinco tratamentos e cinco repetições, sendo a unidade experimental constituída por um aquário com cinco alevinos. As sifonagens foram realizadas duas vezes ao dia às 8 e 17 horas, para retirada de fezes e sobras de ração, com retirada e renovação de $40 \%$ do volume por sifonagem.

As rações experimentais, avaliadas neste segundo experimento, foram formuladas de acordo com os CDas obtidos para o triguilho no experimento 1 . Foram elaboradas cinco rações com níveis de 0,00 ; 7,97; 14,94; 23,91 e 31,88\% de inclusão do triguilho substituindo $100 \%$ do milho, sendo as mesmas isocalóricas, isocálcicas, isofosfóricas e isoprotéicas. As composições percentual e química das rações experimentais estão apresentadas na tabela 2. O arraçoamento foi realizado quatro vezes ao dia, às 8, 11, 14 e 17 horas, com base em $10 \%$ do peso vivo dos animais, mediante biometrias semanais para correção da quantidade de ração fornecida. $\mathrm{O}$ pH, a condutividade elétrica e o oxigênio dissolvido da água foram monitorados semanalmente, enquanto a temperatura foi monitorada diariamente pela manhã e pela tarde.
No final do período experimental, os peixes foram mantidos em jejum por 24 horas. Após este período, foram efetuadas as medidas individuais peso final (PF), comprimento final (CF) e calculados o ganho de peso (GP), a conversão alimentar aparente (CA), a sobrevivência (SO) e o fator de condição (FC). Os dados obtidos foram submetidos à análise de variância em nível de $5 \%$ de probabilidade pelo programa estatístico SAEG (Sistema de Análises Estatísticas e Genéticas) (UFV, 1997).

\section{RESULTADOS E DISCUSSÃO}

Os valores médios dos parâmetros de temperatura, oxigênio dissolvido, $\mathrm{pH}$ e condutividade elétrica observados no experimento 1 foram de $26,03 \pm 0,80^{\circ} \mathrm{C}, 7,68 \pm 1,4 \mathrm{mg} \mathrm{L}^{-1}, 6,44 \pm 0,57$ e $110,35 \pm 35,50 \mu \mathrm{S} \mathrm{cm}^{-1}$, respectivamente. Estes parâmetros estão dentro da faixa aceitável para a criação de peixes de clima tropical (BOYD, 1990; SIPAÚBATAVARES, 1995).

A composição química, o coeficientes de digestibilidade aparente (CDa) e nutrientes digestíveis do triguilho para a tilápia do Nilo estão apresentados na tabela 3 . Os valores de coeficientes de digestibilidade aparente (CDa) do triguilho para a tilápia do Nilo observados neste experimento foram de 91,03\% para a PB e de 78,72\% para a EB. HANLEY (1987) observou CDa da PB do triguilho de $75 \%$, coeficiente este inferior ao observado neste experimento. Os CDas da PB do farelo de trigo para a tilápia do Nilo foi de 78,$21 ; 91,00$ e $91,13 \%$, valores estes observados por FURUYA et al. (2001), BOSCOLO et al. (2002a) e PEZZATO et al. (2002), respectivamente. No entanto, BOSCOLO et al. (2002a) observaram CDa de 96,30\% da PB para o trigo integral, valor este superior ao observado para o triguilho no presente estudo.

Os nutrientes digestíveis avaliados neste trabalho resultaram em 11,92\% de proteína digestível (PD) e 3134,78 Kcal kg-1 para a energia digestível (ED). BOSCOLO et al. (2002a) observaram para o farelo de trigo $13,44 \%$ e para o trigo integral $11,01 \%$ de ED para a tilápia do Nilo; portanto, o triguilho apresenta teor intermediário de PD entre o farelo e o trigo integral.

Quanto ao CDa da EB, HANLEY (1987) observou $57,58 \%$ para o triguilho, valor este inferior ao observado neste experimento. BOSCOLO et al. (2002a), avaliando o CDa do farelo de trigo e do trigo integral para a tilápia do Nilo, observaram 68,81 e 87,07\%, respectivamente. Os valores de ED determinados neste trabalho são inferiores aos observados por BOSCOLO et al. (2002a) para o trigo integral 3423,66Kcal kg-1 e superior aos observados para farelo de trigo 
Tabela 2 - Composição percentual e química das rações experimentais com diferentes níveis de inclusão de triguilho para alevinos de tilápia do Nilo (matéria natural).

\begin{tabular}{|c|c|c|c|c|c|}
\hline \multirow{2}{*}{ Alimentos (\%) } & \multicolumn{5}{|c|}{ Níveis de inclusão de triguilho \% } \\
\hline & 0,00 & 7,97 & 14,94 & 23,91 & 31,88 \\
\hline Milho & 26,45 & 19,84 & 13,22 & 6,61 & 0,00 \\
\hline Triguilho & 0,00 & 7,97 & 14,94 & 23,91 & 31,88 \\
\hline Farelo de soja & 66,60 & 65,47 & 64,35 & 63,22 & 62,06 \\
\hline Calcário calcítico & 1,60 & 1,57 & 1,54 & 1,52 & 1,49 \\
\hline Fosfato bicálcico & 1,85 & 1,82 & 1,79 & 1,75 & 1,72 \\
\hline Óleo de soja & 1,88 & 1,71 & 1,54 & 1,37 & 1,19 \\
\hline Suplemento (min.+vitam.) ${ }^{1}$ & 1,00 & 1,00 & 1,00 & 1,00 & 1,00 \\
\hline Antioxidante (BHT) & 0,02 & 0,02 & 0,02 & 0,02 & 0,02 \\
\hline Sal comum & 0,50 & 0,50 & 0,50 & 0,50 & 0,50 \\
\hline Total & 100,00 & 100,00 & 100,00 & 100,00 & 100,00 \\
\hline \multicolumn{6}{|l|}{ Nutrientes (\%) } \\
\hline Energia digestivel $^{2}$ (kcal/kg) & 3.000 & 3.000 & 3.000 & 3.000 & 3.000 \\
\hline Proteína digestivel $^{2}$ & 30,00 & 30,00 & 30,00 & 30,00 & 30,00 \\
\hline Cálcio & 1,17 & 1,17 & 1,17 & 1,17 & 1,17 \\
\hline Fósforo total & 0,80 & 0,80 & 0,80 & 0,80 & 0,80 \\
\hline Extrato etéreo & 3,70 & 3,28 & 2,87 & 2,45 & 2,04 \\
\hline Ácido Linoléico & 2,00 & 1,83 & 1,674 & 1,51 & 1,34 \\
\hline Amido & 25,47 & 21,20 & 16,92 & 12,65 & 8,38 \\
\hline Fibra bruta & 4,45 & 4,71 & 4,98 & 5,25 & 5,52 \\
\hline Metionina + Cistina & 1,21 & 1,21 & 1,22 & 1,22 & 1,22 \\
\hline Lisina & 1,91 & 1,90 & 1,90 & 1,89 & 1,88 \\
\hline Proteína & 33,56 & 33,56 & 33,56 & 33,56 & 33,56 \\
\hline Metionina & 0,55 & 0,55 & 0,55 & 0,55 & 0,55 \\
\hline
\end{tabular}

${ }^{1}$ Níveis de garantia por quilograma do produto: Vit. A, 500.000UI; Vit. $\mathrm{D}_{3}$, 200.000UI; Vit. E, 5.000mg; Vit. K3, 1.000mg; Vit. B1, 1.500mg; Vit. B2, 1.500mg; Vit. B6, 1.500mg; Vit. B12, 4.000mg; Ác. Fólico, 500mg; Pantotenato Ca, 4.000mg; Vit. C, 15.000mg; Biotina, 50mg; Inositol, 10.000; Nicotinamida, 7.000; Colina, 40.000mg; Co, 10mg; Cu, 500mg; Fe, 5.000mg; I, 50mg; Mn, 1500mg; Se, 10mg; Zn, $5.000 \mathrm{mg}$.

${ }^{2}$ Exigência nutricional baseada no NRC (1993). Baseados nos valores de energia e proteína digestíveis do milho e farelo de soja para tilápia do Nilo propostos por BOSCOLO et al. (2002a).

2825,88Kcal kg-1. Portanto, estas diferenças de nutrientes digestíveis devem ser consideradas para formulação de rações balanceadas.

Os valores médios dos parâmetros físicoquímicos observados durante o experimento 2 foram de $26,6 \pm 1,70^{\circ} \mathrm{C}, 6,9 \pm 0,05 \mathrm{mg} \mathrm{L}^{-1}, 7,8 \pm 0,05$ e $114 \pm 1,27 \mu \mathrm{S}$ $\mathrm{cm}^{-1}$ para temperatura, oxigênio dissolvido, $\mathrm{pH}$ e condutividade elétrica, respectivamente. Segundo BOYD (1990) e SIPAÚBA-TAVARES (1995), estas médias permanecem dentro dos valores recomendados para o desempenho de aqüicultura de peixes em clima tropical.

O peso final (PF), o comprimento final (CF), o ganho de peso (GP), a conversão alimentar aparente (CA), a sobrevivência (SO) e o fator de condição (FC) do experimento de desempenho dos alevinos de tilápias que receberam rações com diferentes níveis de inclusão de triguilho estão apresentados na tabela 4. Não houve diferença significativa $(\mathrm{P}>0,05)$ para os parâmetros de
PF, CF, GP, CA, SO e FC dos alevinos que receberam rações contendo diferentes níveis de inclusão de

Tabela 3 - Composição química, coeficientes de digestibilidade aparente e nutrientes digestíveis do triguilho para a tilápia do Nilo.

\begin{tabular}{ll}
\hline Nutrientes (matéria natural) & $\%$ \\
\hline Proteína bruta & 13,10 \\
Energia bruta (kcal/kg) & 3983 \\
Extrato etéreo & 1,51 \\
Matéria seca & 89,64 \\
Matéria mineral & 1,34 \\
Coeficientes de digestibilidade aparente & \\
Proteína bruta & 91,03 \\
Energia bruta (kcal/kg) & 78,72 \\
Nutrientes digestíveis (matéria natural) & \\
Proteína digestível & 11,92 \\
Energia digestível (kcal/kg) & 3134,78 \\
\hline
\end{tabular}


Tabela 4 - Desempenho de alevinos de tilápias alimentados com rações com diferentes níveis de inclusão de triguilho.

\begin{tabular}{|c|c|c|c|c|c|c|}
\hline \multirow{2}{*}{ Variáveis* } & \multicolumn{5}{|c|}{ Níveis de inclusão de triguilho (\%) } & \multirow{2}{*}{ C.V.\% } \\
\hline & 0,00 & 7,97 & 14,94 & 23,91 & 31,88 & \\
\hline Peso inicial (g) & 0,83 & 0,80 & 0,79 & 0,80 & 0,80 & 5,07 \\
\hline Peso final (g) & 3,64 & 2,29 & 3,18 & 3,50 & 3,09 & 23,72 \\
\hline Comprimento final (cm) & 5,60 & 4,83 & 5,44 & 5,64 & 6,36 & 9,48 \\
\hline Ganho de peso (g) & 2,81 & 1,49 & 2,39 & 2,69 & 2,29 & 31,53 \\
\hline Conversão alimentar aparente & 1,12 & 1,81 & 1,12 & 1,28 & 1,39 & 43,47 \\
\hline Sobrevivência \% & 96,00 & 88,00 & 85,00 & 88,00 & 96,00 & 20,87 \\
\hline Fator de condição & 2,07 & 1,91 & 1,93 & 1,93 & 1,93 & 5,76 \\
\hline
\end{tabular}

*Não houve diferença estatística $(\mathrm{P}>0,05)$.

triguilho substituindo até $100 \%$ do milho. Resultados semelhantes com a utilização de alimentos energéticos ricos em amido na alimentação de tilápias foram observados por BOSCOLO et al. (2002b), os quais relatam não ter observado diferença no desempenho dos animais que receberam farinha de varredura de mandioca nos níveis de 0 a $24 \%$ de inclusão, até a substituição total do milho.

Estes trabalhos confirmam os resultados obtidos por VIOLA \& ARIELI (1983), ANDERSON et al.(1984), DEGANI \& REVACH(1991) e SHIAU (1997), nos quais os autores indicam que a tilápia do Nilo aproveita eficientemente alimentos ricos em amido. A utilização de triguilho, em rações para outros animais, foi realizada com sucesso por BARBOSA et al. (1990) para suínos e ALBINO et al. (1993) para aves, que recomendam a utilização de $30 \%$ de triguilho em rações para estes animais. Além dos aspectos técnicos, a busca por alimentos alternativos de menor custo é muito importante, pois o fator econômico é um entrave para a expansão da piscicultura, pois o alto custo na produção de rações se torna um fator limitante para alcançar desenvolvimento satisfatório da atividade.

\section{CONCLUSÃO}

O coeficiente de digestibilidade aparente do triguilho para alevinos de tilápia do Nilo foi de 91,03\% para a PB e 78,72\% para a EB. O triguilho pode ser incluído em até 31,88\% em rações para alevinos de tilápia do Nilo sem causar prejuízo no desempenho.

\section{AGRADECIMENTO}

Agradecemos ao apoio do Conselho Nacional de Desenvolvimento Científico e Tecnológico, pela concessão da bolsa de iniciação científica PIBIC/CNPq/UNIOESTE, com vigência de 08/2003 a 07/2004.

\section{REFERÊNCIAS}

AKSNES, A.; OPSTVEDT, J. Content of digestible energy in fish feed ingredients determined by the ingredient-substitution method. Aquaculture, v.161, p.45-53, 1998.

ALBINO, L.F.T. et al. Uso do triticale e triguilho em dietas para frango de corte. Concórdia, SC: Embrapa Cnpsa, 1993. p.1-2. (Boletim técnico, v.1, n.1).

ANDERSON, J. et al. Effects of dietary carbohydrats and fibre on the tilápia, Oreochromis niloticus (Linn.). Aquaculture, v.13, p.265-272, 1984.

BARBOSA, H.P. et al. Triguilho na alimentação de suínos. Concórdia: EMBRAPA - CNPSA, 1990. p.1-3. (Comunicado técnico).

BORGHETTI, N.R.B. et al. Aqüicultura: uma visão geral sobre a produção de organismos aquáticos no Brasil e no mundo. Curitiba: Grupo Integrado de Aqüicultura e Estudos Ambientais, 2003. 128p.

BOSCOLO, W.R. et al. Digestibilidade aparente da energia e nutrientes de alimentos convencionais e alternativos para a tilápia do Nilo (Oreochromis niloticus, L.). Revista Brasileira de Zootecnia, v.13, n.2, p.539-545, 2002a.

BOSCOLO, W.R. et al. Farinha de varredura de mandioca (Manihot esculenta) na alimentação de alevinos de tilápia do Nilo (Oreochromis niloticus L.). Revista Brasileira de Zootecnia, v.13, n.2, p.545-551, 2002 b.

BOSCOLO, W.R. et al. Desempenho e características de carcaça de machos revertidos de tilápias do Nilo (Oreochromis niloticus), linhagens tailandesa e comum, nas fases iniciais e de crescimento. Revista Brasileira de Zootecnia, v.30, n.5, p.1391-1396, 2001.

BOYD, C. Water quality in ponds for aquaculture. London: Birmingham, 1990. 482p.

CAStAgnOLli, N. Piscicultura de água doce. Jaboticabal: FUNEP, 1992. 189p.

DE BRUM, P.A.R. et al. Utilização do triguilho em rações para frango de corte. Instrução técnica para o avicultor, 3. Concórdia, SC: Embrapa, 1998. 2p. 
DEGANI, G.; REVACH, A. Digestive capabilities of three commensal fish species: carp, Cyprinus carpio L., tilápia, Oreochromis aureus $X$ O. niloticus, and African catfish, Clarias gariepinus (Burchel 1822). Aquaculture and Fisheries Management, v.22, p.397-403, 1991.

EL-SAYED, A.F.M. Alternative dietary protein sources for farmed tilápia, Oreochromis ssp. Aquaculture, v.179, p.146168, 1999.

FURUYA, W.M. et al. Coeficiente de digestibilidade e valores de aminoácidos digestíveis de alguns ingredientes para a tilápia do Nilo (Oreochromis niloticus). Revista Brasileira de Zootecnia, v.30, n.4, p.1143-1149, 2001.

HANLEY, F. The digestibility for foodstuffs and the effects of feeding selectivity determinations in tilápia (Oreochromis niloticus L.). Aquaculture, v.66, n.2, p.163-179,1987.

HAYASHI,C. et al. Uso de diferentes graus de moagem dos ingredientes em dietas para a tilápia do Nilo (Oreochromis niloticus L.) na fase de crescimento. Acta scientiarum, v.21,n.3,p.733-737,1999.

HILDSORF, A.W.S. Genética e cultivo de tilápias vermelhas, uma revisão. Boletim Instituto de Pesca, v.22, n.1, p.7378, 1995.

KIMURA, F.T.; MILLER, V.L. Improved determination of chromic oxide in cal feed and feces. Journal Agriculture Food Chemistry, v.5, n.2, p.216, 1957.

LUTZ, C.G. Production economics and potential competitive dynamics of commercial tilapia culture in the Americas. In: COSTA-PIERCE, B.A.; RAKOY, J.E. Tilapia aquaculture in the Americas. Baton Rouge: AS, 2000. V.2, p.119-132.
MEURER, F. et al. Lipídeos na alimentação de alevinos revertidos de tilápia do Nilo (Oreochromis niloticus L.). Revista Brasileira de Zootecnia, v.31, n.2, p.566-573, 2002.

MUKHOPADHYAY, N.; RAY, A.K. The apparent and total nutrient digestibility of sal seed (Shorea robusta) meal in rohu, Labeo rohita (Hamilton), fingerlings. Aquaculture Research, v.28, p.683-689, 1997.

NATIONAL RESEARCH COUNCIL - NRC. (Nutrient requirements of warmwater, fishes and shellfishes: nutrient requirements of domestics animals). Washington, 1993. 114p.

PEZZATO, L.E. et al. Digestibilidade aparente de ingredientes pela tilápia do Nilo (Oreochromis niloticus). Revista Brasileira de Zootecnia, v.31, n.4, p.1595-1604, 2002.

SHIAU, S.Y. Utilization of carboydrates in warmwater fish with particular reference to tilápia, Oreochromis niloticus $x \boldsymbol{O}$. aureus. Aquaculture, v.151, p.79-96, 1997.

SILVA, D.J. Análise de alimentos (Métodos químicos e biológicos). Viçosa: UFV, 1990. 165p.

SIPAÚBA-TAVARES, L.H.S. Limnologia aplicada à aqüicultura. Jaboticabal: Funet, 1995. 72p.

SULLIVAN, J.A.; REIGH, R.A. Apparent digestibility of selected feedstuff in diets for hybrid striped bass (Morene saxatilis $\mathrm{x}$ Morena chrysops). Aquaculture, v.138, p.313-322,1995.

UNIVERSIDADE FEDERAL DE VIÇOSA. SAEG - Sistema para análises estatísticas e genética). Versão 7.1. Viçosa, MG, 1997. 150p. (Manual do usuário).

VIOLA, S.; ARIELI, Y. Evaluation of different grains as ingredients in complete feeds for carp and tilápia in intensive culture. Israeli Journal Aquaculture, v.35, p.38-43, 1983. 